\title{
The p97-UBXD8 complex destabilizes mRNA by promoting release of ubiquitinated HuR from mRNP
}

\author{
Hua-Lin Zhou, ${ }^{1,4,5}$ Cuiyu Geng, ${ }^{1}$ Guangbin Luo, ${ }^{1,2}$ and Hua Lou ${ }^{1,2,3,5}$ \\ ${ }^{1}$ Department of Genetics and Genome Sciences, ${ }^{2}$ Case Comprehensive Cancer Center, ${ }^{3}$ Center for RNA Molecular Biology, \\ School of Medicine, Case Western Reserve University, Cleveland, Ohio 44106, USA
}

The assembly and disassembly of ribonucleoproteins (RNPs) are dynamic processes that control every step of RNA metabolism, including mRNA stability. However, our knowledge of how RNP remodeling is achieved is largely limited to RNA helicase functions. Here, we report a previously unknown mechanism that implicates the ATPase p97, a protein-remodeling machine, in the dynamic regulation of mRNP disassembly. We found that p97 and its cofactor, UBXD8, destabilize p21, MKP-1, and SIRT1, three established mRNA targets of the RNA-binding protein $\mathrm{HuR}$, by promoting release of HuR from mRNA. Importantly, ubiquitination of HuR with a short K29 chain serves as the signal for release. When cells are subjected to stress conditions, the steady-state levels of HuR ubiquitination change, suggesting a new mechanism through which HuR mediates the stress response. Our studies reveal a new paradigm in RNA biology: nondegradative ubiquitin signaling-dependent disassembly of mRNP promoted by the p97-UBXD8 complex to control mRNA stability.

[Keywords: HuR; mRNA stability; ubiquitin]

Supplemental material is available for this article.

Received February 7, 2013; revised version accepted April 2, 2013.

RNA-binding proteins (RBPs) recognize specific cis-regulatory mRNA elements to form ribonucleoprotein (RNP) complexes, which control every aspect of the life of a mRNA from pre-mRNA processing to mRNA localization, translation, and turnover (Moore 2005; Keene 2007). A different array of proteins is loaded onto pre-mRNA/ mRNA during every step of post-transcriptional mRNA metabolism, making assembly and disassembly of mRNPs a highly dynamic process. Precise regulation of this process is essential, as failure to assemble or disassemble an appropriate mRNP complex leads to disruption of downstream events such as mRNA export, translation, and decay, which have direct impacts on gene expression (Hieronymus and Silver 2004; Keene 2010; Wilusz and Wilusz 2010). Despite its fundamental importance, our knowledge of mRNP remodeling is limited and mostly emerged from two types of studies involving either RNA helicases or individual protein factors that associate with a defined mRNP in a spatially and/or temporally regu-

\footnotetext{
${ }^{4}$ Present address: State Key Laboratory of Brain and Cognitive Science, Institute of Biophysics, Chinese Academy of Science, Beijing 100101, China.

${ }^{5}$ Corresponding authors

E-mail hua.lou@case.edu

E-mail hlzhou@moon.ibp.ac.cn

Article published online ahead of print. Article and publication date are online at http://www.genesdev.org/cgi/doi/10.1101/gad.215681.113.
}

lated fashion (Hosoda et al. 2006; Tran et al. 2007; Dias et al. 2009; Gehring et al. 2009; Franks et al. 2010).

RNA helicases of the DEAD-box family are an important group of RNA-remodeling proteins. These proteins are ATPases that use ATP to unwind RNA duplexes and remodel RNA-protein complexes (Linder and Jankowsky 2011; Pyle 2011). Distinct RNA helicases play important roles in every step of RNA metabolism (Linder and Jankowsky 2011). However, given the central role of RNA molecules in every aspect of cellular metabolism, it is expected that other types of ATPases function as additional motor proteins in RNA metabolism. In this study, we describe a previously uncharacterized role of a member of the AAA (ATPases associated with diverse cellular activities) family of proteins, vasolin-containing protein (VCP)/p97 (also called cdc48 in yeast), in mRNA stability control.

p97 is considered a protein-remodeling machine (Meyer et al. 2012). It has two ATPase domains, D1 and D2, and uses the energy of ATP hydrolysis to remodel or unfold client proteins (Meyer et al. 2012). An important feature of p97 is that its function is ubiquitin-dependent. In a typical mode of action, p97 recognizes a ubiquitinated client protein through one of its cofactors and uses its ATPase activity to remodel a protein complex by extracting the ubiquitinated protein from the complex (Meyer et al. 2012). It is in this context that p97 is also known as 
a segregase (Ramadan et al. 2007; Acs et al. 2011). Importantly, the extracted ubiquitinated proteins adopt one of two fates. They can be either degraded by the ubiquitin proteasome system (degradative pathway) or deubiquitinated and recycled for future use (nondegradative pathway). Different sets of cofactors cooperate with p97 to confer functional and spatial specificity (Alexandru et al. 2008). The largest p97 cofactor family is the UBX family of ubiquitin receptors that contain an ubiquitin-binding UBA domain and an ubiquitin-like domain, termed the ubiquitin regulatory $\mathrm{X}$ (UBX) domain (Alexandru et al. 2008). UBX proteins act as $\mathrm{p} 97$ cofactors by recruiting ubiquitinated substrate proteins to the complex /Schuberth and Buchberger 2008). Through interaction with its many cofactors, p97 regulates a large number of diverse and independent cellular processes, including fusion of homotypic membranes, nuclear envelope reassembly, and cell cycle progression (Ramadan et al. 2007; Wilcox and Laney 2009; Acs et al. 2011; Verma et al. 2011; Meyer et al. 2012). However, to date, the role of p97 in RNA metabolism has not been characterized.

Recently, we made the unexpected discovery that HuR, an RBP, interacts with a member of the UBX protein family, UBXD8, as well as with p97. This finding led us to investigate the role of p97-UBXD8 in mRNA stability control. HuR is a major mRNA-stabilizing factor, which is known to increase the mRNA half-life of a large number of mRNA targets (Peng et al. 1998; Srikantan and Gorospe 2012). In mammals, stability of many mRNAs encoding inflammatory cytokines, oncoproteins, and G-proteincoupled receptors is regulated by the presence of AU-rich elements (AREs) in their 3' untranslated regions (3' UTR) (Garneau et al. 2007). HuR is one of the many RBPs that bind ARE sequences and plays a vital role in the mammalian stress response, affecting proliferation and survival of cells under stress (Gallouzi et al. 2000; Wang et al. 2000; Hinman and Lou 2008; Srikantan and Gorospe 2012). The HuR protein is believed to bind to AREs on specific target mRNAs, consequently blocking the interaction of mRNA-destabilizing factors with the same AREs (Srikantan and Gorospe 2012).

HuR activity can be regulated by post-translational modifications. The most studied modification of the HuR proteins is phosphorylation. It has been demonstrated that phosphorylation at specific serines or a threonine of HuR can lead to altered cellular localization of the protein and, in one case, can increase the RNA-binding affinity of HuR (Doller et al. 2010; Srikantan and Gorospe 2012). One report indicated that heat shock induces ubiquitination of HuR at Lys 182, leading to degradation of HuR and decreased levels of HuR target mRNA abundance (Abdelmohsen et al. 2009). The HuR proteins have been shown to interact dynamically with their RNA targets in various large mRNPs (Keene 2001; Mukherjee et al. 2009; Masuda et al. 2011). Importantly, two recent genomewide studies revealed that HuR can interact with a large number of mRNAs, underscoring the central role of HuR in mRNA stability control (Lebedeva et al. 2011; Mukherjee et al. 2011). Given that the association of HuR with mRNA targets is a key step in mRNA stabil- ity control, it is imperative to understand how HuRcontaining mRNPs are remodeled.

Here, we report that the ATPase p97 and its cofactor, UBXD8, destabilize p21 mRNA, a well-established target of HuR, by directly releasing ubiquitinated HuR from the mRNP complex formed on p21 mRNA in an ATPand ATPase-dependent manner. Importantly, a K29-linked polyubiquitin chain attached to Lys 313 and Lys 326 (K313/K326) of HuR serves as a signal for the HuR release from an mRNP. Interestingly, ubiquitination of HuR at these lysines does not lead to degradation of HuR. Disruption of K313 and K326 on HuR blocks release of HuR from p21 mRNA and increases p21 mRNA stability. In addition to $\mathrm{HuR}$, the p97-UBXD8 complex can interact with several other RBPs, including $\mathrm{HuC} / \mathrm{HuB} / \mathrm{HuD}$, Fox-1/Fox-2, and CUGBP1, suggesting that the p97-UBXD8 complex has a widespread role in regulating RBP activities. Our studies reveal a new paradigm in RNA biology: ubiquitin signaling-dependent disassembly of mRNP mediated by the p97-UBXD8 complex to regulate mRNA stability.

\section{Results}

\section{p97 and UBXD8 destabilize p21 mRNA}

We recently identified an RNA-independent interaction of HuR with p97 and its cofactor, UBXD8, in HeLa cells (Fig. 1A; Supplemental Fig. S1A,B). UBXD7, another member of the UBX protein family, does not interact with HuR (Supplemental Fig. S1C). Note that overexpression of UBXD8 in cells did not alter the p97 level in cells (Supplemental Fig. S1D).p97 and UBXD8 interact with HuR as a complex, as siRNA knockdown of either p97 or UBXD8 abolishes the interaction (Fig. 1B,C). This interaction is also direct, indicated by a Maltose-binding protein $(\mathrm{MBP})$ pulldown assay using recombinant proteins (Fig. 1D).

At steady state, UBXD8 is localized predominantly in cytoplasmic compartments, while HuR is mostly detected in the nucleus with a low amount in the cytoplasm (Supplemental Fig. S1E). Coimmunoprecipitation (co-IP) analysis indicated that the interaction of HuR and UBXD8 occurs in the cytoplasm but not in the nucleus (Supplemental Fig. S2). Truncation mutant data indicate that the UBX domain and, to a lesser extent, the UBA domain of UBXD8 and the RRM3 domain of HuR are critical for this interaction (Supplemental Fig. S3).

Given the localization of UBXD8 and the well-characterized role of HuR in mRNA stability control (Peng et al. 1998; Abdelmohsen et al. 2007), we investigated whether the p97-UBXD8 complex plays a role in mRNA stability control. We used a previously characterized HuR target, p21 mRNA, as the model substrate in this study (Wang et al. 2000). It has been demonstrated that HuR stabilizes p21 mRNA by binding to an ARE in the 3' UTR of p21 (Wang et al. 2000). Knockdown of p97 or UBXD8 by two different siRNAs for each gene in HeLa cells significantly increased steady-state levels of both mRNA and protein of the endogenously expressed p21 (Fig. 2A,B). Analysis of mRNA half-life indicates that knockdown of p97 or UBXD8 increased the half-life of p21 mRNA 
A

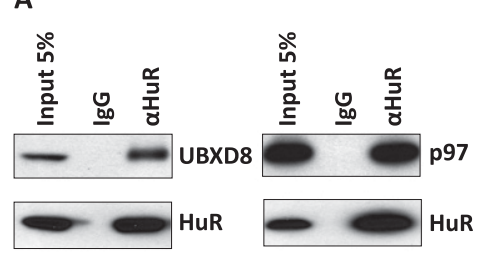

B

C

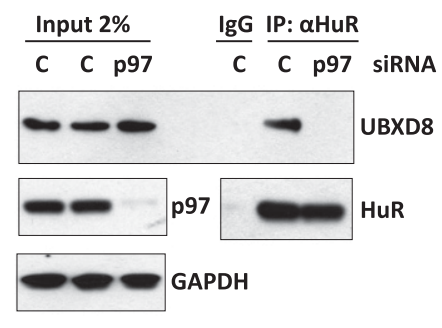

D
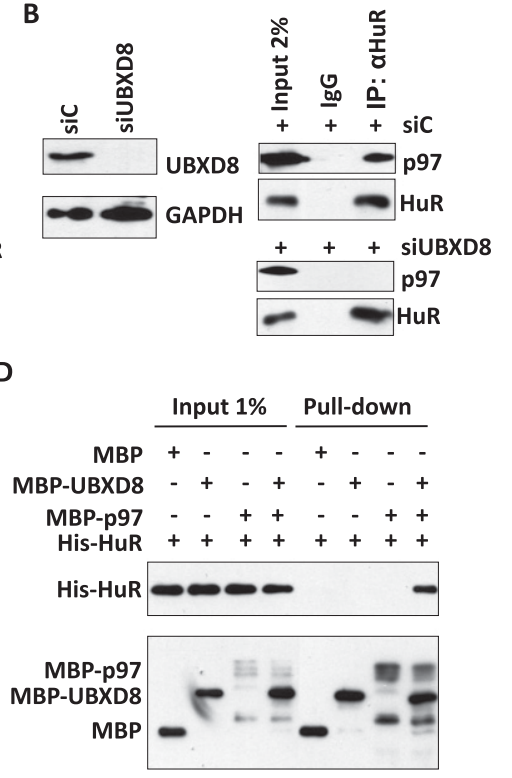

Figure 1. HuR interacts with UBXD8 and p97. (A) CoIP assay using HeLa cell lysate. Immunoprecipitation antibody: $\alpha$ HuR; Western blot antibody: $\alpha$ UBXD8, $\alpha p 97$, or $\alpha$ HuR. $(B, C)$ Co-IP assay. HeLa cells were treated with control siRNA (siC), siRNA against UBXD8 $(B)$, or siRNA against $\mathrm{p} 97(C)$ before co-IP experiment. $(B, C$, left panel) siRNA knockdown efficiency. Western blot antibody: $\alpha$ UBXD 8 and $\alpha$ GAPDH in $B ; \alpha \mathrm{p} 97$ and $\alpha \mathrm{GAPDH}$ in $C$. (B,C, right panel) Co-IP assay. Immunoprecipitation antibody: $\alpha \mathrm{HuR}$; Western blot antibody: $\alpha$ UBXD8, $\alpha$ p97, or $\alpha$ HuR. $(D)$ MBP pull-down assay. MBP fusion proteins were incubated with HisHuR. The mixture was pulled down using amylose resin and probed with $\alpha \mathrm{HuR}$ (top panel) or $\alpha \mathrm{MBP}$ (bottom panel). from $5 \mathrm{~h}$ to 10 or $8 \mathrm{~h}$, respectively (Fig. 2C). siRNA knockdown of HuR decreased the half-life of p21 mRNA, consistent with previous studies (Fig. 2C; Wang et al. 2000).

\section{The effect of p97-UBXD8 on p21 mRNA is mediated by $\mathrm{HuR}$}

To determine whether the regulation of $\mathrm{p} 21 \mathrm{mRNA}$ stability by p97 and UBXD8 depends on HuR, we conducted the following two experiments. First, we used a previously described reporter that contains the luciferase coding sequence fused to the 3' UTR region of $\mathrm{p} 21$ to test whether the ARE on p21 mRNA is required for the regulation (Wang et al. 2000). Knockdown of p97 or UBXD8 increased luciferase activity from the reporter that contains the full-length p21 3' UTR (pGL3-FL) but had no effect on a reporter without the p21 3' UTR (pGL3) or a reporter in which the ARE sequence was deleted from the p21 3' UTR (pGL3- $\triangle \mathrm{B} 2$ ), indicating that the p97UBXD8-dependent destabilization of the p21 mRNA is mediated by the HuR target sequence (Fig. 2D). Second, we combined siRNA knockdown of either p97 or UBXD8 with HuR siRNA knockdown to investigate whether regulation of p21 mRNA stability by p97-UBXD8 required HuR. The effect of the p97 or UBXD8 knockdown on p21 mRNA accumulation was significantly reduced when HuR was knocked down, indicating that the p97-UBXD8dependent destabilization of the p21 mRNA is mediated through HuR (Fig. 2E). Western blot analysis demonstrated that the expression level of p21 protein is, in general, consistent with the p21 mRNA level (Fig. 2B,F). We conclude from these results that destabilization of mRNA by the p97-UBXD8 complex is mediated by HuR.

Notably, in all of the siRNA knockdown experiments shown in Figure 2, knockdown of p97 had a stronger effect than knockdown of UBXD8. Furthermore, when siRNAs against p97 and UBXD8 were used in combination, the effect remained the same as when siRNA against p97 was used alone. These results suggest that, in addition to UBXD8, p97 may regulate p21 mRNA stability through other ubiquitin receptors, which recognize other RBPs that also regulate p 21 mRNA stability. This is not surprising, as p21 mRNA stability is under the control of several factors (Jung et al. 2010).

Consistent with a general role in mRNA stability control, p97-UBXD8 has a similar effect on the mRNA level of two additional HuR target RNAs: MKP-1 and SIRT1 (Supplemental Fig. S4A,B; Abdelmohsen et al. 2007; Kuwano et al. 2008).

\section{Ubiquitination of the HuR protein}

Considering that $\mathrm{p} 97$ functions by recognizing ubiquitinated protein substrates (Schuberth and Buchberger 2008; Meyer et al. 2012), we asked whether HuR protein could be ubiquitinated in HeLa cells. We transfected HeLa cells with His-tagged ubiquitin (His-Ub) and affinity-purified His-tagged proteins under denaturing conditions. When the His-tagged proteins were immunoblotted using antiHuR antibody, multiple slow-moving bands were observed that are indicative of ubiquitination of the endogenously expressed HuR proteins (Fig. 3A). The ubiquitin chains on HuR are of different lengths, typical of polyubiquitinated proteins (Alexandru et al. 2008). The apparent molecular weight $(50 \mathrm{kDa})$ of the major ubiquitinated HuR suggests the presence of two ubiquitins (Fig. 3A, lane 3). Cotransfecting HeLa cells with HA-Ub and Myc-HuR followed by immunoprecipitation/Western blot analysis reveals a major ubiquitinated Myc-HuR protein conjugated to two ubiquitins (Fig. 3B, lane 9; Supplemental Fig. S5A, lane 9), similar to the endogenous HuR. Interestingly, we also detected Myc-HuR proteins with very long ubiquitin chains (Fig. 3B, lane 9; Supplemental Fig. S5A, lane 9). Using ubiquitin mutant constructs containing a single wild-type Lys residue at position $6,11,29,48$, or 63 , we 


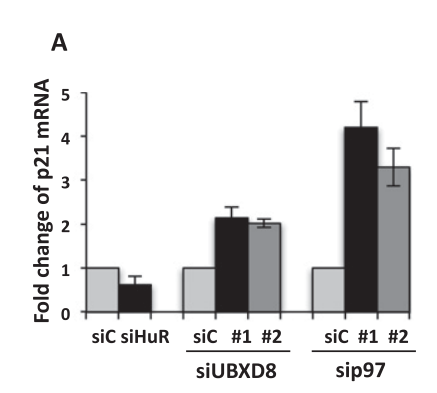

B
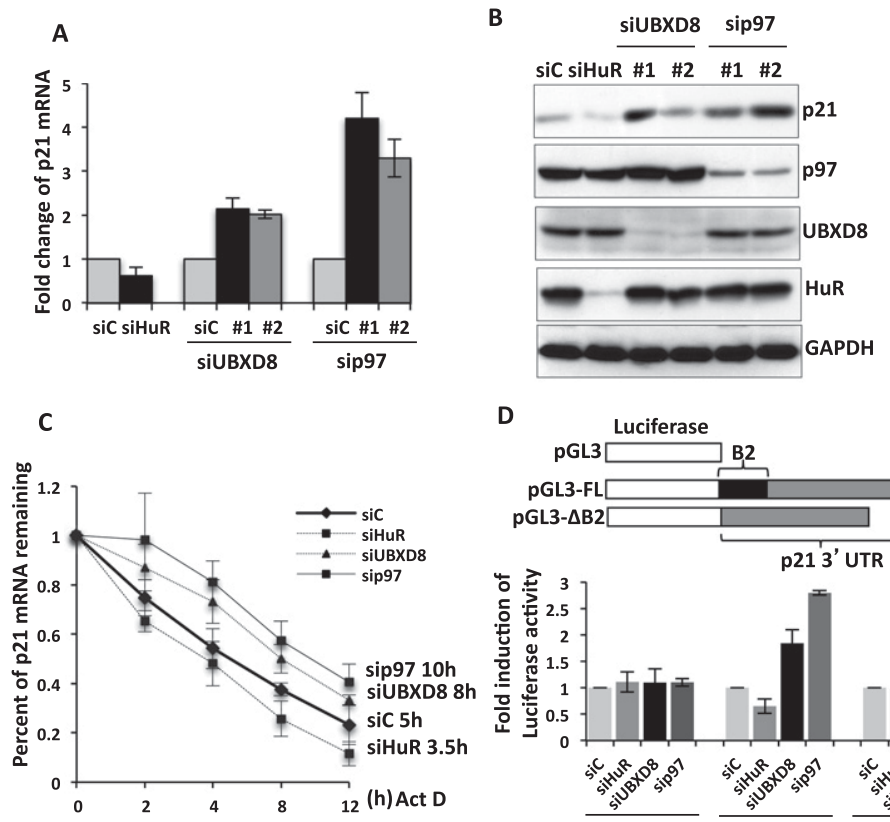

D
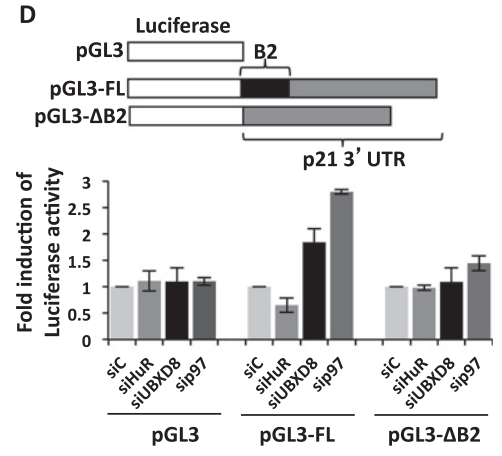

$\mathbf{E}$

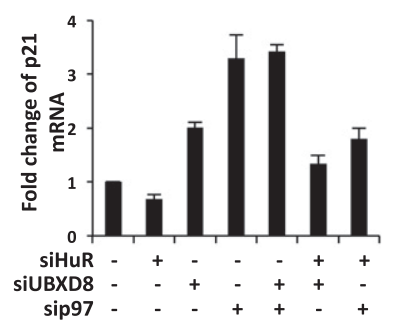

F

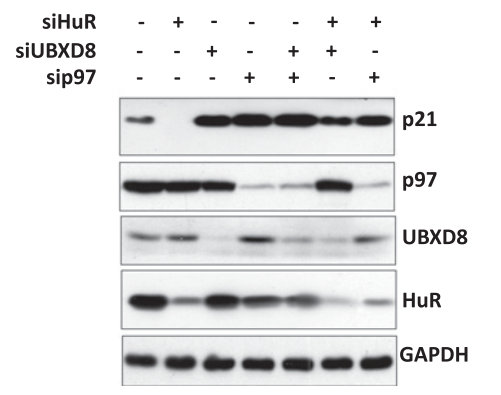

Figure 2. UBXD8 and p97 affect $\mathrm{p} 21 \mathrm{mRNA}$ and protein levels in HeLa cells in a HuR-dependent manner. (A) Real-time RT-PCR to analyze p21 mRNA levels in control siRNA-treated (siC), siUBXD8-treated, or sip97treated cells. Two independent siRNAs were used to knock down either UBXD8 or p97. (B) Western blot indicating knockdown efficiency and p 21 protein levels in treated cells. $(C)$ p21 mRNA half-life measurement after siRNA knockdown of UBXD8, p97, or HuR. (D) Effect of siRNA knockdown of UBXD8 or p97 on the p21 reporter indicated by a luciferase activity assay. B2 represents ARE regulated by HuR. (E) Real-time RTPCR analysis of p21 mRNA level after siRNA knockdown of UBXD8 or p97 in HuR-depleted cells. $N \geq 3$. $(F)$ Western blot indicating knockdown efficiency and p21 protein levels in treated cells as described in $E$. found that only HA-UbK29 led to significant ubiquitination of HuR (Fig. 3B, lane 12; Supplemental Fig. S5A, lane 12). A similar experiment using ubiquitin mutants in which only one Lys was substituted by an Arg indicated that K29R ubiquitin significantly reduced attachment of short polyubiquitin chains, particularly the one with a molecular weight equivalent to two ubiquitins, but not long polyubiquitin chains (>250 kDa) (Supplemental Fig. $\mathrm{S} 5 \mathrm{~B}$, lane 8 ). In contrast, K48R ubiquitin significantly affected long but not short polyubiquitin chain attachment to HuR (Supplemental Fig. S5B, lane 9). These results suggest that HuR can be conjugated to two types of polyubiquitin chains: the major, short K29 polyubiquitin chains and the minor, long K48 polyubiquitin chains.

To investigate whether ubiquitinated HuR undergoes degradation, we transfected HeLa cells with HA-Ub and cultured cells in the absence or presence of the proteasome inhibitor MG132. We immunoprecipitated the total proteins extracted from the transfected cells with antiHuR antibody followed by Western blot analysis with anti-HA antibody. Treatment of cells with MG132 increased the cellular level of ubiquitinated proteins in general (Fig. 3C, lanes 1,2). Interestingly, MG132 did not affect the levels of the short polyubiquitin chains on Myc-HuR but increased accumulation of the long K48linked polyubiquitin chains, indicating that the K29linked polyubiquitin chains act as nonproteolytic signals, while the K48-linked chains serve as signals for HuR protein degradation (Fig. 3C, lanes 3,4). It has been reported that heat-induced linkage of the K48 polyubiquitin chain targets the HuR protein for proteasome-dependent degradation (Abdelmohsen et al. 2009), whereas the function of the K29-linked polyubiquitin chain on HuR has not been documented.

To determine whether UBXD8 interacted with the K29-linked ubiquitin chain on $\mathrm{HuR}$, we carried out a two-step immunoprecipitation experiment. We cotransfected cells with Flag-UBXD8, Myc-HuR and HA-Ub, HA-UbK29R, or HA-UbK29. In the first immunoprecipitation, we used anti-Flag antibody to immunoprecipitate proteins that are associated with Flag-UBXD8. As expected, Myc-HuR was detected in the precipitated proteins (Fig. 3D, lane 5). To determine whether the interaction between UBXD8 and Myc-HuR involves the ubiquitin chain on Myc-HuR, we carried out a second-step immunoprecipitation by immunoprecipitating the Flag-UBXD8 complex with anti-HA antibody. As shown in lane 8 in Figure 3D, Myc-HuR was detected after the sequential 
Zhou et al.

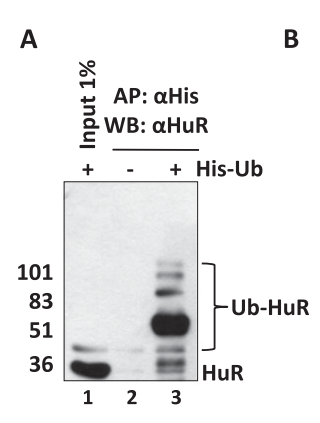

B
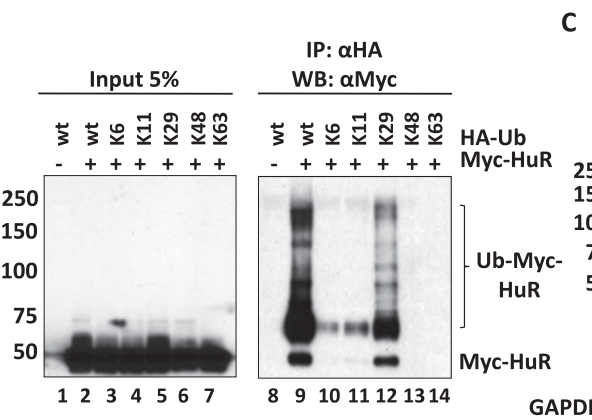

C
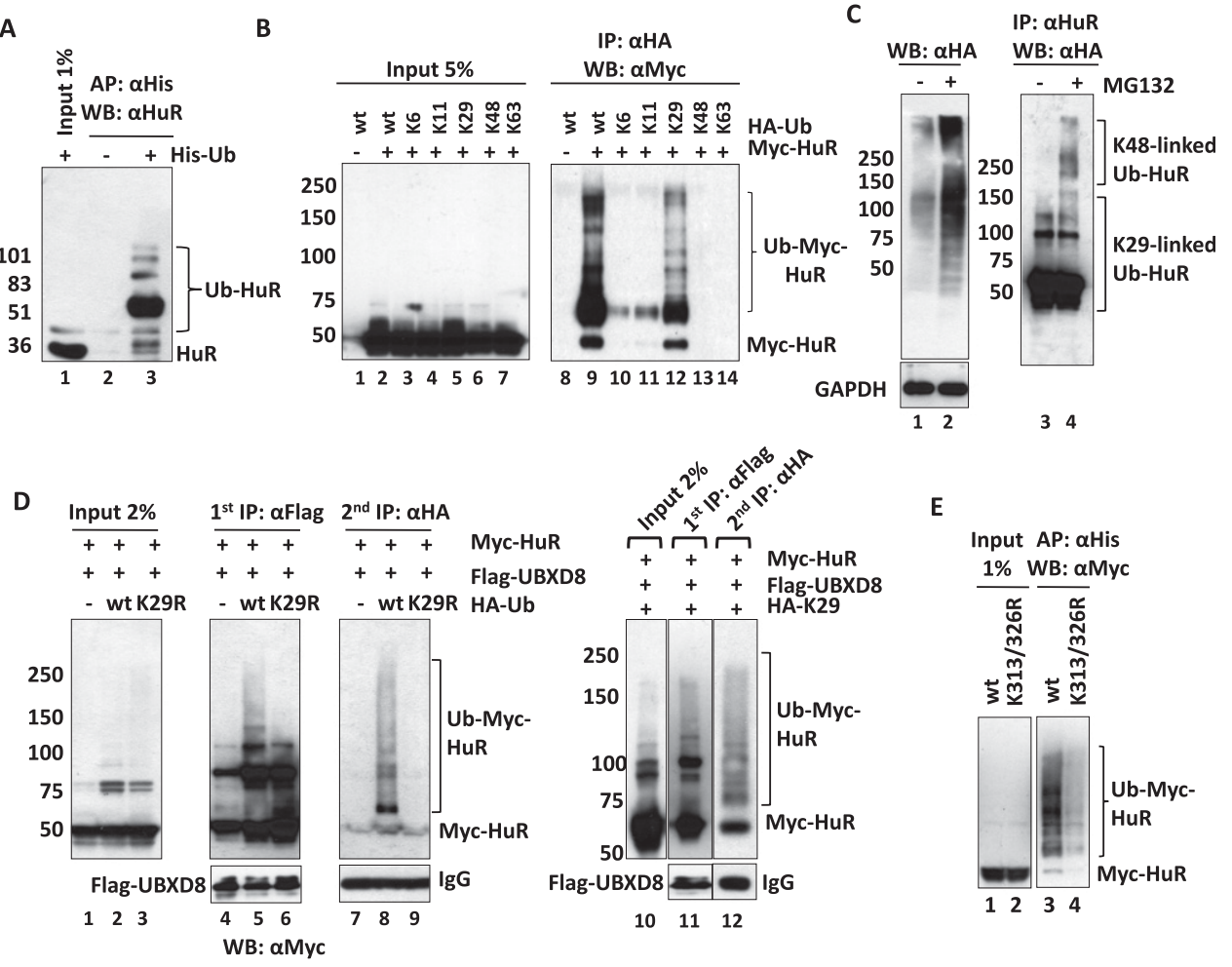

Figure 3. Ubiquitination of HuR. (A) Endogenously expressed HuR is ubiquitinated. The His-tagged proteins isolated from His-Ub transfected HeLa cells were affinity-purified under denaturing conditions. Western blot antibody: $\alpha$ HuR. (AP) Affinity purification. (B) Co-IP to detect ubiquitination of Myc-HuR. The protein lysate isolated from HeLa cells cotransfected with Myc-HuR and wild-type or mutant HA-Ub was immunoprecipitated under nondenaturing conditions with mouse $\alpha \mathrm{HA}$ antibody and probed with rabbit $\alpha \mathrm{Myc}$ antibody in Western blot. (C) Co-IP analysis to detect ubiquitination of endogenous HuR in MG132-treated cells. Cells were transfected with HA-Ub and then treated with MG132. (Left panel) Western blot with either $\alpha H A$ or $\alpha$ GAPDH antibody. (Right panel) Immunoprecipitation with mouse $\alpha \mathrm{HuR}$ antibody under nondenaturing conditions and Western blot with rabbit $\alpha \mathrm{HA}$ antibody. Note that the unubiquitinated HuR was detected most likely due to the oligomerization of HuR proteins (Fialcowitz-White et al. 2007). (D) Twostep immunoprecipitation to show that UBXD8 interacts with K29-linked ubiquitin chain on the HuR protein. HeLa cells were cotransfected with Flag-UBXD8, Myc-HuR, and either no ubiquitin (lanes 1,4,7), HA-Ub (lanes 2,5,8), HA-K29R-Ub (lanes 3,6,9), or HAK29-Ub (lanes 10-12). First-step immunoprecipitation antibody: mouse $\alpha$ Flag; second-step immunoprecipitation antibody: mouse $\alpha H A$; Western blot antibody: rabbit $\alpha$ Myc, $\alpha$ Flag, or $\alpha \operatorname{IgG}$. The immunoprecipitated proteins from the first-step immunoprecipitation were used for the second-step immunoprecipitation. $(E)$ Co-IP to detect ubiquitination site on HuR. Cells were cotransfected with His-Ub and either wild-type or the K313/326R mutant Myc-HuR. The His-tagged proteins in the cell lysate were affinity-purified under denaturing conditions and probed with $\alpha$ Myc antibody in Western blot.

immunoprecipitations, indicating that UBXD8 interacts with ubiquitinated HuR. When HA-UbK29 was used, similar results were observed (Fig. 3D, lanes 10-12). When HA-UbK29R in which Lys 29 is mutated to Arg was used, Myc-HuR was not detected after the second immunoprecipitation (Fig. 3D, lane 9). These results demonstrate that UBXD8 interacted specifically with the K29-linked ubiquitin chain on HuR. As only a few reports discussed the function of the K29-linked polyubiquitin chain (Ikeda et al. 2010), our study provides an exciting opportunity to investigate the role of this specific ubiquitin linkage.

\section{Reduced ubiquitination of HuR increases the level of p21 mRNA}

To analyze the role of the K29-linked polyubiquitin chains in HuR function, we carried out deletion and point mutation analyses to identify the lysines on the HuR protein that are linked to ubiquitin. By domain deletion analysis, the ubiquitin sites were mapped to RRM3 of HuR (Supplemental Fig. S6A,B). Within RRM3, when three of the seven lysines (K271, K313, and K326) were mutated individually or two lysines (K282 and K283) were mutated simultaneously, ubiquitination of $\mathrm{HuR}$ was reduced significantly, while mutation of K320 or K323 had no effect (Supplemental Fig. S6C). Importantly, when K313R and $\mathrm{K} 326 \mathrm{R}$ were combined, ubiquitination of HuR was almost abolished (Fig. 3E). An in vitro ubiquitin assay further confirmed that the recombinant wild-type HuR, but not HuRK313/326R, could be ubiquitinated (Supplemental Fig. S7).

To characterize the role of HuR ubiquitination in mRNA stability control, we expressed siRNA-resistant wild-type or mutant K313/326R HuR in HeLa cells treated with a HuR-specific siRNA at levels comparable with the endogenous HuR (Fig. 4A). The mutations did not affect 
A

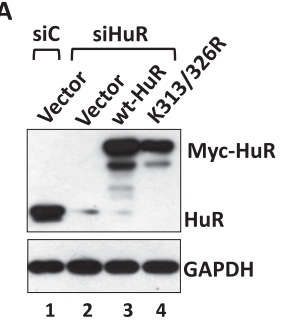

C

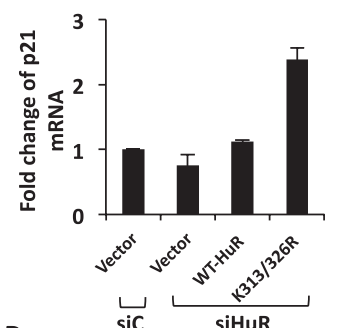

D

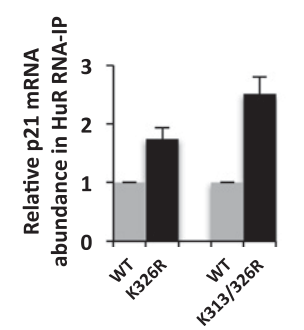

B

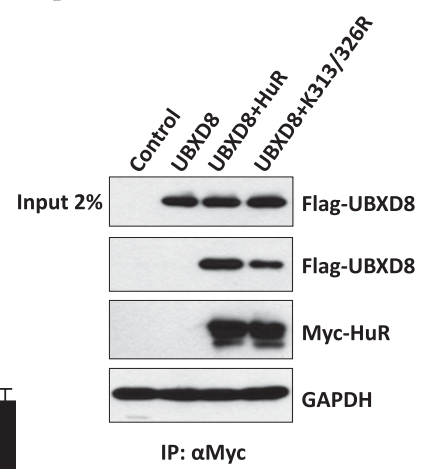

E

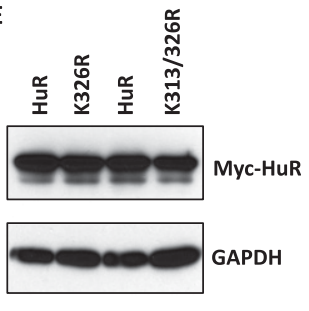

Figure 4. Ubiquitination of HuR affects its ability to stabilize mRNA. (A) HuR replacement experiment. Cells were treated with control siRNA or siHuR. The siHuR-treated cells were also transfected with vector alone, Myc-HuR, or Myc-HuRK313/ $326 \mathrm{R}$. Western blot was probed with $\alpha \mathrm{HuR}$ or $\alpha \mathrm{GAPDH}$ antibody. $(B)$ Interaction of HuR and UBXD8 was reduced by lysine mutations (K313/326R) on HuR. HeLa cells were treated with HuR-specific siRNA and cotransfected with Flag-UBXD8 and siRNA-resistant Myc-HuR or Myc-HuR313/326R. Co-IP analysis. Immunoprecipitation antibody: rabbit $\alpha \mathrm{Myc}$; Western blot antibody: mouse $\alpha$ Flag, $\alpha$ Myc, or $\alpha \mathrm{GAPDH}$. (C) Effect of the treatment in $A$ on p21 mRNA levels detected by real-time RTPCR assay. $N \geq 3$. (D) Effect of treatment in HuR lysine mutations on association of wild-type or mutant HuR with p21 mRNA by RNA immunoprecipitation analysis using $\alpha$ Myc antibody. $N \geq 3$. (E) Western blot showing protein expression of wild-type or mutant Myc-HuR. Antibody: $\alpha$ Myc or $\alpha \mathrm{GAPDH}$.

half-life, RNA-binding ability, or cellular localization of the mutant HuR protein (Supplemental Fig. S8A-C). However, the mutant HuR protein showed decreased interaction with UBXD8 (Fig. 4B). This result suggests that although unubiquitinated HuR is capable of interacting with the p97-UBXD8 complex (Fig. 1D), ubiquitination of HuR strengthens these interactions.

Interestingly, the level of p21 mRNA was twofold higher in HuRK313/326R-expressing cells compared with wild-type HuR-expressing cells (Fig. 4C). Note that the p21 level showed a moderate decrease in cells treated with HuR-specific siRNA (Fig. 4C, cf. first and second bars). However, as documented in previous studies (Wang et al. 2000), the effect of HuR on the p21 level is much stronger after cells were treated with UV irradiation

(Supplemental Fig. S9). An RNA immunoprecipitation showed that the increased level of p21 mRNA is due to the increased association of the mutant HuR (Fig. 4D-E; Supplemental Fig. S10A), suggesting that ubiquitination of HuR triggers its dissociation from mRNA, thereby decreasing the stability of its target mRNAs. These results imply a previously unknown mechanism that uses nonproteolytic ubiquitin signaling to regulate mRNA stability.

The p97-UBX protein complexes participate in various cellular functions by interacting with a specific ubiquitinated substrate in a complex and promoting dissociation of the substrate protein from the complex using the ATPase activity of p97 (Meyer et al. 2012). Given the tight interactions between HuR and p97-UBXD8, we hypothesized that p97-UBXD8 regulates HuR-mediated mRNA stability control by releasing HuR from an mRNP complex. An RNA immunoprecipitation analysis indicated that knockdown of p97 or UBXD8 increased association of HuR with p21 mRNA (Fig. 5A,B), while reintroduction of p97 that is resistant to the siRNA in increasing concentrations decreased association (Fig. 5C,D; Supplemental Fig. S10B,C). Cellular localization and, more importantly, protein levels of HuR in treated cells were not altered, further supporting that the ubiquitin chain on HuR acts as a nondegradative signal (Fig. 5A; Supplemental Fig. S11). Association of HuR with MPK-1 and SIRT1
A

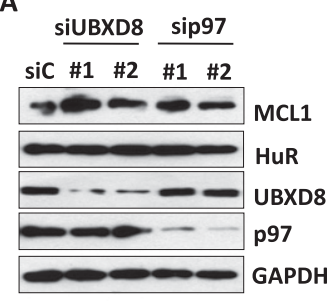

C

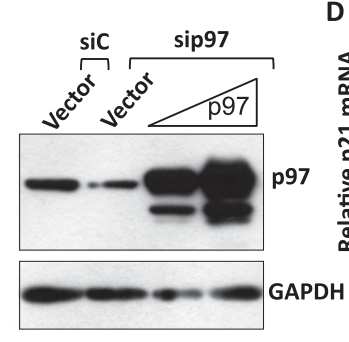

B

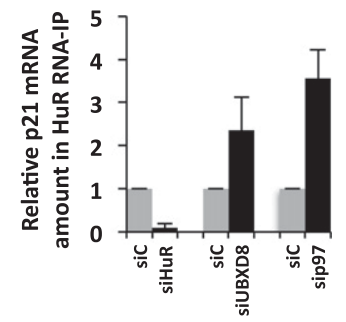

D

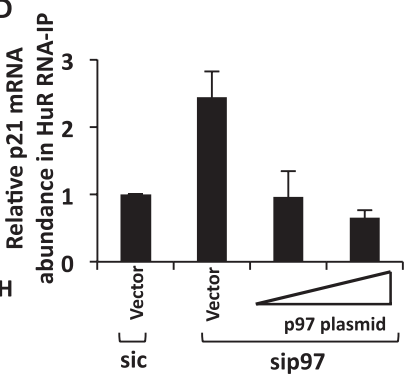

Figure 5. Effect of knockdown of UBXD8 or p97 on association of HuR with p21 mRNA. $(A, B)$ Cells were treated with control siRNA (siC) or siRNA targeting UBXD8 or p97. (A) Western blot using $\alpha M C L 1, \alpha H u R, \alpha U B X D 8, \alpha p 97$, or $\alpha$ GAPDH antibodies. (B) HuR association with p21 mRNA was determined by RNA immunoprecipitation using $\alpha \mathrm{HuR}$ antibody followed by realtime RT-PCR analysis. $N \geq 3$. $(C, D)$ HeLa cells cotransfected with control siRNA (siC) or siRNA targeting p97 and siRNAresistant Flag-p97 expression vector $(0.2$ or $2 \mu \mathrm{g})$. (C) Western blot analysis. Western blot antibody: $\alpha$ p 97 or $\alpha \mathrm{GAPDH}$. $(D)$ RNA immunoprecipitation analysis using $\alpha \mathrm{HuR}$. Real-time RT-PCR analysis on p21 mRNA was carried out. $N=3$. 
is also reduced in p97 or UBXD8 siRNA-treated cells (Supplemental Fig. S4C,D).

\section{p97-UBXD8 promotes release of ubiquitinated $\mathrm{HuR}$ from $m R N P$}

To determine whether the p97-UBXD8 complex can directly promote release of HuR from p21 mRNA, the in vitro HuR-releasing assay diagrammed in Figure 6A was carried out. Total protein extract isolated from cells overexpressing Myc-HuR and HA-Ub was incubated with a biotin-labeled RNA oligonucleotide that contains the p21 ARE sequence. The complexes formed on the p21 RNA were bound to streptavidin beads and incubated with recombinant p97 and UBXD8 in the presence of ATP. After separation of the supernatant from the beads, HuR was detected by Western blot analysis. Thus, the HuR detected in the supernatant represents protein that was released from the complexes formed on the p 21 RNA. We found that ubiquitinated HuR was preferentially released from the mRNA complexes in a time-dependent fashion (Fig. 6B), indicating that the p97-UBXD8 complex can indeed release HuR from mRNP complexes. Importantly, this release is dependent on ATP and the ATPase activity of p97 (Fig. 6C,D). The mutant p21 RNA had no effect on HuR binding and release (Supplemental Fig. S12A,B). These results reveal a previously unknown mechanism of mRNP disassembly that is catalyzed by the p97 ATPase. However, we do acknowledge the possibility that the observed release of HuR may be caused by an indirect mechanism, as these experiments used cell extract containing many RBPs.

To define the role of HuR ubiquitination in dissociation, we replaced the wild-type HuR with HuRK313/326R in the HuR-releasing assay, which revealed that the efficiency of HuR release was greatly reduced (Fig. 6E, cf. the 30-min and 60-min lanes). Importantly, the release of HuR depends on its ubiquitination, as demonstrated by the lack of release when recombinant $\mathrm{HuR}$ was used in this assay (Supplemental Fig. S12C). Replacement of HA-Ub by HA-K29R-Ub, but not by HAK48R-Ub, also reduced the efficiency of HuR release (Fig. 6F), indicating that the K29-linked ubiquitin chain is crucial.

To examine release of RNA from the HuR-containing RNPs, we carried out a p21 RNA-releasing assay. In this experiment, an RNP complex was formed by incubating the HuR-containing complex isolated from cells transfected with Myc-HuR and HA-Ub with p21 RNA. This RNP complex was then incubated with p97, UBXD8, and ATP. In a time-course experiment, we observed increased release of p21 RNA in the released fraction over time (Supplemental Fig. S12D).

\section{Ubiquitination of $H u R$ is regulated under stress}

Taken together, our results support a model in which $\mathrm{HuR}$ associates with mRNA to form a dynamic mRNP complex. K29-linked polyubiquitin chains attached to HuR provide a signal for dissociation of HuR from mRNA. The p97-UBXD8 complex recognizes and releases ubiquitinated HuR from mRNPs (Fig. 7A).

We hypothesized that this dynamic process is tightly regulated. The well-established HuR-mediated stress responses provide a great opportunity to address this issue. Stress-induced HuR binding to target mRNAs has been shown to be a key step for HuR protein-mediated stress regulation (Gallouzi et al. 2000; Abdelmohsen et al.
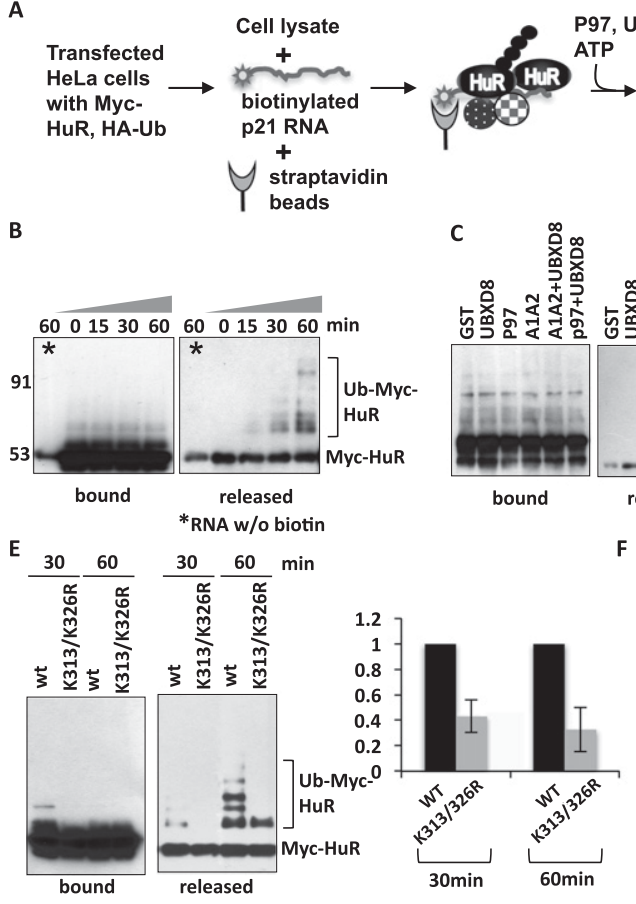

C

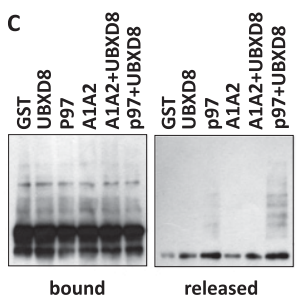

$\mathbf{F}$

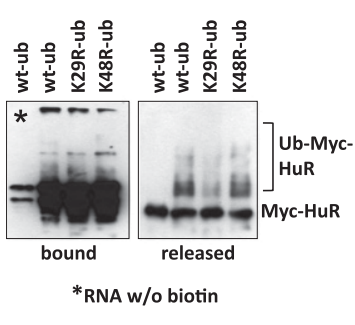

Figure 6. Releasing HuR from p21 RNA catalyzed by the p97-UBXD8 complex. (A) Schematic diagram of the experimental procedure for the HuR-releasing assay. $(B-F)$ After incubation of Myc-HuR-containing RNP with recombinant UBXD8 and p97 for the indicated time (60 min if not shown), the bound and released Myc-HuR were separated and Western blotprobed with $\alpha$ Myc antibody. $(B)$ Time-course experiment using wild-type proteins for all of the protein components used in this assay. $(C)$ Test of ATPase activity of $\mathrm{p} 97$ and UBXD8 dependence. (A1A2) ATPase-inactive p97 mutant. (D) Test of ATP dependence. AMP-PNP is an ATP analog. $(E)$ Test of ubiquitination dependence on the HuR protein. MycHuRK313/326R instead of Myc-HuR was used in transfection. The graph shows the amounts of the released mutant Myc-HuR relative to the wild-type Myc-HuR, which was set as $1 . N=3 .(F)$ Test of specific ubiquitin chain dependence. Mutant HA-Ub expression vectors were used for transfection in comparison with the wild-type HA-Ub. 
A

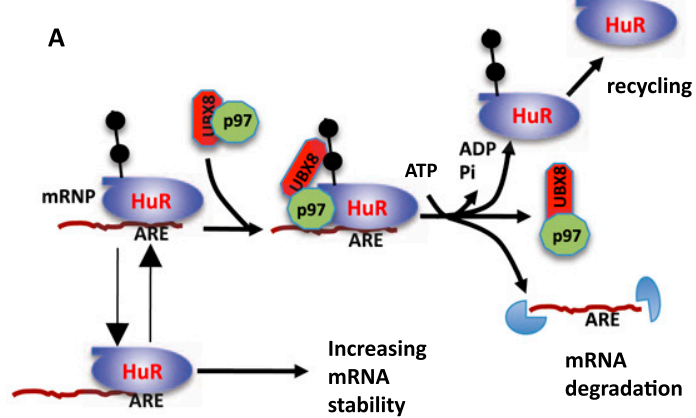

Figure 7. (A) Model of regulated HuR-mRNA interaction by ubiquitin signaling. $(B, C)$ Co-IP assay to detect ubiquitination of HuR in HeLa cells transfected with Myc-HuR and HA-Ub after cells were treated with UVC irradiation $\left(60 \mathrm{~J} / \mathrm{m}^{2}\right)$ and allowed to recover for up to $24 \mathrm{~h}$ or with heat shock for up to $2 \mathrm{~h}$ at $45^{\circ} \mathrm{C}$. The cell lysate was immunoprecipitated with mouse $\alpha \mathrm{HA}$ antibody and probed with rabbit $\alpha$ Myc antibody in the Western blot analysis.

2008). It has been reported that stresses induce HuR to change its association with a large number of target mRNAs, which leads to alterations in mRNA abundance (Abdelmohsen et al. 2007; Masuda et al. 2011). After UV treatment, HuR ubiquitination in HeLa cells was reduced starting between 4 and $8 \mathrm{~h}$ during recovery after the treatment (Fig. 7B). The level of p21 mRNA and its binding to $\mathrm{HuR}$ were also increased at the same time (Supplemental Fig. S13). Heat-shock treatment similarly reduced HuR ubiquitination (Fig. 7C). These results indicate that ubiquitination of $\mathrm{HuR}$ is regulated by adverse physiological conditions.

\section{Interaction of RBPs with $p 97$ and UBXD8}

To determine whether the p97-UBXD8 complex has a general role in regulating activity of RBPs, we carried out co-IP experiments. We transfected HeLa cells with Flagtagged p97 or UBXD8 and Myc-tagged RBPs. Of the seven additional RBPs tested, Fox-1, Fox-2, CUGBP1, HuB, HuC, and $\mathrm{HuD}$ can interact with p97 and UBXD8 (Supplemental Fig. S14). In contrast, Tra-2 did not show an interaction (Supplemental Fig. S14). Note that most of these proteins have enriched expression in neurons. These results strongly imply that p97 and UBXD8 use a similar mechanism to regulate the activity of multiple RBPs in addition to $\mathrm{HuR}$.

\section{Discussion}

The p97-UBXD8 complex mediates mRNP disassembly

The studies reported here demonstrate that the p97UBXD8 complex uses its segregase activity to release ubiquitinated HuR protein from its mRNP and destabilizes mRNA (diagrammed in Fig. 7A), a previously unknown mechanism of mRNP disassembly. Assembly and disassembly of mRNPs are dynamic processes that occur during the entire life of an mRNA molecule, thus directly impacting the proteomic composition of a cell (Keene 2001). Studies have demonstrated that RNA helicases are major players in catalyzing mRNP disassembly. For example, the RNA helicase UPF1 can disassemble the NMD complex, which is required to complete the NMD process and recycle factors involved in NMD (Franks et al. 2010). The DEAD-box protein Dbp5 is essential for mRNA export from the nucleus and has been implicated in the dynamics of mRNP complexes in late steps of mRNA export associated with the nuclear pore (Tran et al. 2007). Here we show for the first time that p97, an ATPase that is distinct from RNA helicases, can also disassemble mRNP complexes as RNA helicases do. These studies have significant implications for our understanding of mRNP remodeling.

p97 is one of the best-characterized members of the type II AAA ATPase family. It is an essential and highly conserved chaperone-related protein involved in a large variety of cellular processes, including ubiquitindependent protein degradation and processing, fusion of homotypic membranes, nuclear envelope reassembly, cell cycle progression, and others (Yamanaka et al. 2011; Meyer et al. 2012). However, a role for p97 in controlling gene expression post-transcriptionally has not been documented. Thus, mRNP disassembly catalyzed by p97 represents a new function of $\mathrm{p} 97$.

Specificity of p97 cellular function is determined by numerous different cofactors, of which UBX proteins constitute the largest known protein family. UBXD8 is a member of the UBX family proteins. This protein is known to be associated with endoplasmic reticulum (ER) and lipid droplets through a transmembrane domain and involved in ER-associated protein degradation and lipid metabolism (Zehmer et al. 2009; Lee et al. 2010; Suzuki et al. 2012). Here we demonstrate a previously uncharacterized function of UBDX8, which involves mRNP 
remodeling. It is possible that UBXD8 controls mRNA stability while it is anchored in ER membrane with its UBA and UBX domains oriented in the cytosol (Lee et al. 2010). It is also conceivable that under specific conditions, a fraction of UBXD8 moves to the cytoplasm with the help of chaperone proteins and regulates mRNA metabolism in the cytoplasm.

\section{Ubiquitin signaling in mRNA stability control}

The control of gene expression is coordinated at multiple levels such as transcription, processing, export, and degradation. The steady-state mRNA level is the result of two opposing biological processes: transcription and degradation, both of which are important points to regulate gene expression (Garneau et al. 2007). Recent studies have demonstrated a major role for mRNA degradation in the control of gene expression. It was estimated that $40 \%-50 \%$ of changes in gene expression in response to cellular signals occur at the level of mRNA stability (Fan et al. 2002; Cheadle et al. 2005). There is a growing notion that ubiquitin signaling plays an important role in the post-transcriptional regulation of gene expression. Recently, several studies have suggested a role for the ubiquitin system in regulating various aspects of posttranscriptional gene expression (Brooks 2010). However, these studies, particularly those related to mRNA stability control, have focused on the role of ubiquitin signaling in targeting proteins for degradation. For example, one report demonstrated that the rapid turnover of an AREcontaining mRNA is associated with the ubiquitination and degradation of members of the AUF1 family of AREbinding proteins (Laroia et al. 1999). Another study demonstrated that heat shock induces ubiquitin-mediated proteolysis of $\mathrm{HuR}$ and destabilizes $16 \mathrm{HuR}$ target mRNAs (Abdelmohsen et al. 2009). In contrast, the role of nondegradative ubiquitin signaling in mRNA stability control has not been investigated. Thus, our studies reveal a new mechanism that uses nondegradative ubiquitin signaling to regulate mRNP disassembly and mRNA stability.

Although nondegradative effects of protein ubiquitination is an emerging and exciting area of research in ubiquitin biology, there are only a few examples that are well characterized (Chen and Sun 2009). The role of ubiquitin signaling in mRNP remodeling will provide another important example for the nondegradative function of protein ubiquitination.

\section{Stress response and ubiquitination of $\mathrm{HuR}$}

HuR plays an important role in cellular stress responses. It has been reported that stresses induce HuR to change its association with a large number of target mRNAs, which leads to alterations in mRNA abundance (Abdelmohsen et al. 2007; Masuda et al. 2011). Regulated phosphorylation of HuR has been demonstrated to contribute to HuR-mediated stress response (Abdelmohsen et al. 2007; Kim et al. 2008; Doller et al. 2010; Masuda et al. 2011). Our studies indicate that UVC irradiation and heat shock can change the ubiquitination levels of HuR, which provides important new clues to understanding how the HuR-mediated stress response is achieved. We show that the ubiquitin conjugated to HuR serves as a signal for HuR to dissociate from its target mRNA (Fig. 7A). We suggest that the dynamic ubiquitination and deubiquitination of HuR serves as an additional mechanism to rapidly alter HuR activity in response to cellular stresses in the precise control of the abundance of HuR target mRNAs. It remains to be investigated how the different signaling pathways interact and coordinate with each other to mount an appropriate response to a specific stimulus in a timely and controlled fashion.

There are seven Lys residues in ubiquitin, allowing for seven possible homotypic linkage types and multiple possible heterotypic chains conjugated to target proteins (Amerik and Hochstrasser 2004), which serve as versatile signaling messengers in various cellular functions. Compared with the well-known K48- or K63-linked polyubiquitin chain, the role of the K29-linked polyubiquitin chain is not clearly understood. Although they represent $3 \%$ of all types of polyubiquitin chains, K29-linked polyubiquitin chains have only been studied in a few reports that suggest their involvement in protein degradation (Xu et al. 2009; Kim et al. 2011). In our study, the K29-linked polyubiquitin chain on $\mathrm{HuR}$ acts as a nondegradative signal to modulate HuR function, which is a previously uncharacterized function.

Our studies demonstrate that HuR can be conjugated to two types of polyubiquitin chains: the major, short K29linked polyubiquitin chain and the minor, long K48linked polyubiquitin chain. Our results strongly imply that the K29-linked chain on HuR functions as a nondegradative signal, while the K48-linked chain on HuR functions as a signal for protein degradation (Fig. 3C; Supplemental Fig. S5). Our results are consistent with a previous study demonstrating that heat-shock-induced proteolysis of HuR involves long ubiquitination chains (Abdelmohsen et al. 2009). In that case, ubiquitination occurs on K182, which is distinct from the lysines involved in the K29 chain ubiquitination characterized in our study (Abdelmohsen et al. 2009). It is intriguing that in response to heat-shock treatment, the ubiquitination levels of HuR change for both types of polyubiquitin chains, with an increase of K48-linked chain and a decrease of K29-linked chain (Fig. 7C; Abdelmohsen et al. 2009). How the two processes coordinate with each other is an interesting question for future studies. It is entirely possible that HuR ubiquitination using different polyubiquitin chains regulates a distinct subset of HuR target mRNAs.

\section{p97 plays a general role in post-transcriptional gene regulation}

Our findings that UBXD8-p97 interacts with several RBPs strongly imply that UBXD8-p97 plays a previously unappreciated general role in post-transcriptional regulation by recognizing and rearranging RNP complexes. Interestingly, although mutations in p97 have been identified 
in families with inclusion body myopathy, Paget disease, Frontotemporal Dementia (IBMPFD), and amyotrophic lateral sclerosis (ALS) (Lukong et al. 2008; Johnson et al. 2010), the molecular mechanisms of pathogenesis for these diseases are not fully understood. Based on our data, it is conceivable that the underlying cause of the severe neuron-degenerative diseases associated with mutations of p97 (Watts et al. 2004; Johnson et al. 2010; Ritz et al. 2011) includes misregulation of post-transcription processes.

\section{Materials and methods}

\section{Plasmids}

The cell expression plasmids pCS2-Flag-p97 and pCS2-FlagA1A2 were generated by inserting full-length mouse p97 cDNA or A1A2 (gift from Changcheng Song, NIH) in-frame into pCS2Flag. HuR truncation or lysine mutants were generated by PCR-mediated cloning using full-length mouse HuR cDNA as a template. UBXD8 truncation mutants were generated by PCRmediated cloning using full-length mouse UBXD8 cDNA /gift from Raymond J. Deshaies, California Institute of Technology) as a template and were cloned into the pCS2-Flag. The mammalian cell expression plasmids pcDNA3-HA-Ub, pcDNA3-HA-UbK6, pcDNA3-HA-UbK11, pcDNA3-HA-UbK29, pcDNA3-HA-UbK48, and pcDNA3-HA-UbK63 were obtained from Tomohiko Ohta (St. Marianna University School of Medicine, Japan). The mammalian cell expression plasmids pCS2-HA-Ub with a single LysArg mutation (K11R, K29R, K48R, or K63R) were generated by inserting ubiquitin cDNAs from the pET-His6-Ub plasmids (gift from Tomohiko Ohta, St. Marianna University School of Medicine, Japan) into pCS2-HA. The pMBL-UBXD8-His6, pMBLp97-His6, pMBL-A1A2-His6, pMBL-HuR-His6, or pMBL-K313/ 326R-His6 plasmids used to make recombinant proteins were generated by PCR-mediated cloning. The DNA primers used to generate the expression plasmids are shown in Supplemental Table S1.

\section{Cell culture, siRNA, treatment, and reporter assay}

HeLa cell transfection, total RNA isolation, random primermediated reverse transcription, and real-time PCR were described previously (Zhou et al. 2011). siRNA-mediated protein depletion was used in HeLa cells. Two UBXD8 or two p97 siRNA oligonucleotides targeting different sequences were purchased from Dharmacon (siGENOME SMARTpool siRNA) and Santa Cruz Biotechnology (sc-60607 for UBXD8, and sc-37187 for p97). The HuR siRNA that targets the 3' UTR of HuR (AAUCUUAA GUUUCGUAAGUUA) and the p97 siRNA that targets the 3' UTR of p97 (CAAUAAACGUUGGGUCAAAUU) were purchased from Dharmacon. Two-hundred picomoles of siRNA oligonucleotides was transfected into HeLa cells using Dharmafectin according to the protocol suggested by the manufacturer. For the mRNA stability assay, the amounts of p21/MKP-1/SIRT1 mRNA were normalized with amounts of GAPDH mRNA. The fold difference between treated $(\mathrm{T})$ and control $(\mathrm{C})$ cells was calculated as $\left(\mathrm{Ct}^{\mathrm{C}-\mathrm{GAPDH}} \times \mathrm{Ct}^{\mathrm{T}-\mathrm{p} 21}\right) /\left(\mathrm{Ct}^{\mathrm{C}-\mathrm{p} 21} \times \mathrm{Ct}^{\mathrm{T}-\mathrm{GAPDH}}\right)$. The results shown are representatives of at least three independent experiments. To analyze the effect of stress on HuR ubiquitination, cells were treated with UVC $\left(60 \mathrm{~J} / \mathrm{m}^{2}\right)$ and allowed to recover for up to $24 \mathrm{~h}$. For heat-shock treatment, cells were incubated with preheated medium for up to $2 \mathrm{~h}$ at $45^{\circ} \mathrm{C}$. To analyze the effect of proteasome inhibitors on HuR ubiquitination, $48 \mathrm{~h}$ after transfection, HeLa cells were treated with
MG132 $(20 \mu \mathrm{M})$ for $3 \mathrm{~h}$. To analyze the half-life of p21 mRNA, $48 \mathrm{~h}$ after siRNA transfection, HeLa cells were treated with actinomycin $\mathrm{D}(5 \mu \mathrm{M})$ for the indicated periods of time. For the reporter assay, HeLa cells on a $6-\mathrm{cm}$ plate were transfected with 200 pmol of siRNA oligonucleotides using Lipofectamine RNAiMAX (Invitrogen) and the reverse transfection protocol suggested by the manufacturer. After $24 \mathrm{~h}$, cells were cotransfected with 200 pmol of siRNA oligonucleotides, $0.5 \mu \mathrm{g}$ of pGL-p2 1 reporter plasmids, and $0.5 \mu \mathrm{g}$ of internal pRL-control plasmids. After $48 \mathrm{~h}$, cells were collected, and Luciferase activity was measured by using the Dual-Luciferase Reporter Assay system (Promega) according to the manufacturer's instructions. The fold difference between treatment $(\mathrm{T})$ and control $(\mathrm{C})$ was calculated as $\left(\mathrm{Ct}^{\mathrm{C}-\mathrm{RL}} \times \mathrm{Ct}^{\mathrm{T}-\mathrm{GL}}\right) /\left(\mathrm{Ct}^{\mathrm{C}-\mathrm{GL}} \times \mathrm{Ct}^{\mathrm{T}-\mathrm{RL}}\right)$.

\section{Co-IP and Western blot analysis}

The co-IP and Western blot analyses were carried out as described (Zhou et al. 2011). In these experiments, antibodies were used against HuR (3A2 from Santa Cruz Biotechnology), HuB (Millipore), HuC (Millipore), MCL-1 (S-19 from Santa Cruz Biotechnology), UBXD8 (IMGENEX), p97 (Fitzgerald), p21 (Abcam), Myc (Invitrogen and Sigma), Flag (Sigma), and HA (Roche and Sigma). The anti-c-Myc and anti-Flag agarose affinity gels used for immunoprecipitation were purchased from Sigma. Two-step immunoprecipitation was carried out as described (Ramadan et al. 2007). Briefly, first-step immunoprecipitation was eluted with $1 \%$ SDS buffer and then diluted to $0.1 \%$ SDS in PBS containing $1 \%$ BSA and $1 \%$ Triton X-100 before the subsequent immunoprecipitation.

\section{RNA immunoprecipitation}

Immunoprecipitation of endogenous RNA-protein complexes was previously described (Tenenbaum et al. 2002). Immunoprecipitated RNA and the total RNA from input were purified with TRIzol (Invitrogen). RNAs were dissolved in $30 \mu \mathrm{L}$ of RNase-free $\mathrm{TE}$, and $8 \mu \mathrm{L}$ was used for reverse transcription per $20-\mu \mathrm{L}$ reaction with random primers following the manufacturer's protocol (Invitrogen). The cDNA (2 $\mu \mathrm{L}$ per well) was used for real-time PCR. Amounts of p21/MKP-1/SIRT1 mRNA purified by immunoprecipitation were normalized with amounts of their input mRNA. The fold difference between treatment $(\mathrm{T})$ and control $(\mathrm{C})$ was calculated as $\left(\mathrm{Ct}^{\mathrm{C}-\text { Input }} \times \mathrm{Ct}^{\mathrm{T}-\mathrm{IP}}\right) /\left(\mathrm{Ct}^{\mathrm{C}-\mathrm{IP}} \times \mathrm{Ct}^{\mathrm{T}-\text { Input }}\right)$.

\section{Immunostaining}

HeLa cells were plated on glass coverslips in six-well plates and allowed to attach overnight. After the appropriate experimental treatments, cells were washed three times in phosphate-buffered saline $(1 \times \mathrm{PBS})$, fixed in $4 \%$ phosphate-buffered paraformaldehyde, and permeabilized in $0.5 \%$ PBS-goat serum with Triton or $0.5 \%$ PBS-BSA with Triton. After permeabilization, cells were incubated with primary antibodies for $1 \mathrm{~h}$ at room temperature and then incubated with secondary antibodies conjugated with fluorescein.

\section{Fractionation of nuclear or cytoplasm proteins}

HeLa cells $\left(2 \times 10^{7}\right)$ on tissue culture plates were washed twice with cold PBS and collected by scraping. Cell pellets were lysed in $500 \mu \mathrm{L}$ of buffer A (10 mM HEPES at $\mathrm{pH} 7.9,10 \mathrm{mM} \mathrm{KCl}$, $1.5 \mathrm{mM} \mathrm{MgCl}_{2}, 1 \mathrm{mM}$ DTT, protease inhibitor cocktail) for $10 \mathrm{~min}$ on ice. The lysates were homogenized with a microcentrifuge sample pestle (Fisherbrand). Nuclei were pelleted by 
centrifugation at $1300 \mathrm{~g}$ for $5 \mathrm{~min}$ at $4^{\circ} \mathrm{C}$, and the supernatant containing cytoplasmic proteins was collected and stored on ice. Nuclei pellet were washed once in buffer A and then lysed in $500 \mu \mathrm{L}$ of buffer B (20 mM HEPES at pH 7.9, $400 \mathrm{mM} \mathrm{NaCl}, 25 \%$ glycerol, $1 \mathrm{mM}$ EDTA, $1 \mathrm{mM}$ DTT, $1.5 \mathrm{mM} \mathrm{MgCl}_{2}$, protease inhibitor cocktail) through vortexing periodically for $30 \mathrm{~min}$ at $4^{\circ} \mathrm{C}$. Supernatants containing soluble nucleic proteins were collected by centrifugation at $25,000 \mathrm{~g}$ for $20 \mathrm{~min}$ and stored on ice. The concentrations of nuclear and cytoplasmic proteins were measured, and the same amounts of proteins were used for immunoprecipitation or ubiquitination analysis.

\section{RNA mobility shift assay}

The 5' end of the 42-base-pair (bp) p21 RNA (UCUUAAUU AUUAUUUGUGUUUUAAUUUAAACACCUCCUCAUG; Dharmacon) was labeled with $\gamma_{-}{ }^{32} \mathrm{P}$-ATP by T4 polynucleotide kinase. RNPs were assembled with $1 \mathrm{nM}{ }^{32} \mathrm{P}$-labeled RNA in a binding buffer (20 mM HEPES at pH 7.5, $100 \mathrm{mM} \mathrm{NaCl}, 3 \mathrm{mM}$ $\mathrm{MgCl}_{2}$, and $10 \%\left[\mathrm{w} / \mathrm{v}\right.$ ] glycerol) for $30 \mathrm{~min}$ at $30^{\circ} \mathrm{C}$ with increasing amounts of recombinant $\operatorname{HuR}(0,50$, or $100 \mathrm{ng})$. After incubation for $30 \mathrm{~min}$ at $30^{\circ} \mathrm{C}$, RNP complexes were resolved by native gel electrophoresis on an $8 \%$ polyacrylamide gel and detected by autoradiography.

\section{Protein purification}

To produce recombinant proteins for UBXD8, p97, p97A1A2, HuR, and HuRK313/326R, the cDNAs for these proteins were fused with MBP and His6. The fusion proteins were prepared using the pMAL Protein Fusion and Purification System kit (New England Biolabs) first, and the MBP was cleaved by Factor $\mathrm{Xa}$. The resulting proteins were then separated from the cleaved MBP using HisPur Cobalt Resin (Pierce). Purified proteins were dialyzed against Roeder D.

\section{MBP pull-down assay}

One microgram of MBP, MBP-UBXD8, or MBP-p97 proteins was immobilized on $30 \mu \mathrm{L}$ of amylose resin and incubated with $1 \mu \mathrm{g}$ of His-HuR for $4 \mathrm{~h}$ at $4^{\circ} \mathrm{C}$ in column buffer (20 mM Tris/ $\mathrm{HCl}$ at $\mathrm{pH} 7.4,15 \%$ glycerol, $200 \mathrm{mM} \mathrm{NaCl}, 5 \mathrm{mM}$ EDTA, $1 \times$ proteinase inhibitor). After the resin was washed six times with column buffer, bound proteins were eluted in $60 \mu \mathrm{L}$ of $2 \times$ loading dye. His-HuR and MBP fusion proteins were immunoblotted by anti-HuR and anti-MBP antibody, respectively.

\section{HuR ubiquitination analysis}

Purification of denatured His-Ub conjugates was modified from a previously described procedure (Xirodimas et al. 2001). Briefly, $48 \mathrm{~h}$ post-transfection, cells were lysed in $6 \mathrm{~mL}$ of $6 \mathrm{M}$ guanidinium- $\mathrm{HCl}, 0.1 \mathrm{M} \mathrm{Na}_{2} \mathrm{HPO}_{4} / \mathrm{NaH}_{2} \mathrm{PO}_{4}, 0.01 \mathrm{M}$ Tris/ $\mathrm{HCl}$ $(\mathrm{pH} 8.0), 5 \mathrm{mM}$ imidazole, and $10 \mathrm{mM} \beta$-mercaptoethanol. Onehundred microliters of HisPur Cobalt Resin (Pierce) was then added, and lysates were rotated for $4 \mathrm{~h}$ at room temperature. The beads were successively washed with each of the following buffers: $6 \mathrm{M}$ guanidinium- $\mathrm{HCl}, 0.1 \mathrm{M} \mathrm{Na}_{2} \mathrm{HPO}_{4} / \mathrm{NaH}_{2} \mathrm{PO}_{4}$, and $0.01 \mathrm{M}$ Tris/ $\mathrm{HCl}(\mathrm{pH}$ 8.0) plus $10 \mathrm{mM} \beta$-mercaptoethanol; $8 \mathrm{M}$ urea, $0.1 \mathrm{M} \mathrm{Na}_{2} \mathrm{HPO}_{4} / \mathrm{NaH}_{2} \mathrm{PO}_{4}, 0.01 \mathrm{M}$ Tris/HCl (pH 8.0), and $10 \mathrm{mM} \beta$-mercaptoethanol; $8 \mathrm{M}$ urea, $0.1 \mathrm{M} \mathrm{Na}_{2} \mathrm{HPO}_{4} / \mathrm{NaH}_{2} \mathrm{PO}_{4}$, $0.01 \mathrm{M}$ Tris/ $\mathrm{HCl}$ (pH 6.3), and $10 \mathrm{mM} \beta$-mercaptoethanol (buffer A) plus $0.2 \%$ Triton $\mathrm{X}-100$; and then buffer A plus $0.1 \%$ Triton $\mathrm{X}-100$. After the last wash, His6-tagged ubiquitinated proteins were eluted by incubating the beads with $75 \mu \mathrm{L}$ of $200 \mathrm{mM}$ imidazole, $0.15 \mathrm{M}$ Tris $/ \mathrm{HCl}(\mathrm{pH} 6.7$ ), 30\% glycerol, $0.72 \mathrm{M}$ $\beta$-mercaptoethanol, and 5\% SDS for $20 \mathrm{~min}$ at room temperature. The eluates were analyzed by Western blot analysis.

To analyze ubiquitination of exogenously expressed HuR, HeLa cells cotransfected with Myc-HuR and HA-Ub were lysed in EBC lysis buffer $(50 \mathrm{mM}$ Tris at $\mathrm{pH} 8.0,120 \mathrm{mM} \mathrm{NaCl}, 0.5 \%$ NP-40, proteinase inhibitor cocktail, $10 \mathrm{mM} \mathrm{N}$-ethylaleimide). Protein lysate was incubated with mouse anti-HA antibodycoated beads or rabbit anti-Myc agarose affinity gel (Sigma) for $6 \mathrm{~h}$ at $4^{\circ} \mathrm{C}$. After six washes with NETN, proteins were eluted from the beads using $2 \times$ loading buffer for $4 \mathrm{~min}$ at $100^{\circ} \mathrm{C}$. Eluted proteins were resolved by $4 \%-15 \%$ SDS-PAGE Criterion Precast Gel (Bio-Rad) followed by Western blot detection using rabbit anti-Myc antibody or mouse anti-HA antibody. In vitro ubiquitin assay was performed according to the manufacturer's instructions (Enzo Life Science) using $10 \mathrm{nM} \mathrm{HuR}$ or HuRK313/326R.

\section{HuR-releasing assay}

HeLa cells cotransfected with Myc-HuR and HA-Ub were lysed with EBC lysis buffer. The cell extract was dialyzed against Roeder D and used for the binding assay. Five-hundred nanomolar wild-type or mutant p21 RNA oligonucleotide that was biotinylated at its $5^{\prime}$ end (wild type, UCUUAAUUAUUAUUU GUGUUUUAAUUUAAACACCUCCUCAUG; mutant, UCG GACGUGGGAGUCGUGCGGUAGGGUGCACACCUCCUC ACG; Dharmacon) was incubated with $50 \mu \mathrm{L}$ of cell extract $(18 \mu \mathrm{g} / \mu \mathrm{L})$ to form RNPs in a binding buffer (20 mM HEPES at $\mathrm{pH} 7.5,100 \mathrm{mM} \mathrm{NaCl}, 3 \mathrm{mM} \mathrm{MgCl} 2,10 \%$ [w/v] glycerol, 0.2 $\mathrm{U} / \mu \mathrm{L}$ RNaseOUT, $25 \mu \mathrm{g} / \mathrm{mL}$ tRNA, proteinase inhibitor cocktail) for $2 \mathrm{~h}$ at $4^{\circ} \mathrm{C}$. RNPs were then incubated with streptavidin agarose beads (Millipore) for $3 \mathrm{~h}$ at $4^{\circ} \mathrm{C}$. After six washes in wash buffer (10 mM Tris at $\mathrm{pH} 8.0,500 \mathrm{mM} \mathrm{NaCl}, 1 \mathrm{mM}$ EDTA), streptavidin-bound RNPs were used in the HuR-releasing assay. Recombinant p97 and UBXD8 were added to the RNPs at a final concentrations of $250 \mathrm{nM}$. The reactions were incubated in ATP or other adenosine nucleotides (ADP and AMP-PNP; SigmaAldrich) at $0.5 \mathrm{mM}$ for the indicated times in Figure 5 at $30^{\circ} \mathrm{C}$ in $100 \mu \mathrm{L}$ of reaction buffer $(20 \mathrm{mM}$ HEPES at $\mathrm{pH} 7.5,100 \mathrm{mM}$ $\mathrm{NaCl}, 3 \mathrm{mM} \mathrm{MgCl} 2,10 \%$ [w/v] glycerol). The supernatant and bound fractions were separated by centrifugation. Thirty microliters of the supernatant containing released $\mathrm{HuR}$ and $10 \mu \mathrm{L}$ of bound HuR that was eluted by $200 \mu \mathrm{L}$ of elution buffer $10 \mathrm{mM}$ Tris at $\mathrm{pH}$ 6.0, $2 \mathrm{M} \mathrm{NaCl}, 1 \mathrm{mM}$ EDTA, $0.5 \mathrm{M} \mathrm{MgCl}_{2}$ ) were used in Western blot analysis. Quantification of the releasing assay was performed using ImageJ software. The released ubiquitinated $\mathrm{HuR}$ was normalized to the bound $\mathrm{HuR}$, and the value for the wild-type $\mathrm{HuR}$ at each time point was set as 1 .

\section{p21 RNA-releasing assay}

HeLa cells cotransfected with Myc-HuR and HA-Ub were lysed with EBC lysis buffer. The cell extract was dialyzed against Roeder D and used for the binding assay. Five-hundred nanomolar p21 RNA oligonucleotide was incubated with $50 \mu \mathrm{L}$ of cell extract $(18 \mu \mathrm{g} / \mu \mathrm{L})$ to form RNPs in a binding buffer $(20 \mathrm{mM}$ HEPES at $\mathrm{pH} 7.5,100 \mathrm{mM} \mathrm{NaCl}, 3 \mathrm{mM} \mathrm{MgCl}_{2}, 10 \%[\mathrm{w} / \mathrm{v}]$ glycerol, $0.2 \mathrm{U} / \mu \mathrm{L}$ RNaseOUT, $25 \mu \mathrm{g} / \mathrm{mL}$ tRNA, proteinase inhibitor cocktail) for $2 \mathrm{~h}$ at $4^{\circ} \mathrm{C}$. RNPs were then incubated with anti-c-Myc agarose affinity gel (Sigma) for $3 \mathrm{~h}$ at $4^{\circ} \mathrm{C}$. After six washes in wash buffer (10 mM Tris at $\mathrm{pH} 8.0,500 \mathrm{mM} \mathrm{NaCl}$, $1 \mathrm{mM}$ EDTA), the bound RNPs were used in the RNA-releasing assay. Recombinant p97 and UBXD8 were added to the RNPs at final concentrations of $250 \mathrm{nM}$. The reactions were incubated in the presence of $0.5 \mathrm{mM}$ ATP for the indicated times at $30^{\circ} \mathrm{C}$ in $100 \mu \mathrm{L}$ of reaction buffer (20 mM HEPES at $\mathrm{pH} 7.5,100 \mathrm{mM}$ $\mathrm{NaCl}, 3 \mathrm{mM} \mathrm{MgCl} 2,10 \%$ [w/v] glycerol). The supernatant and 
bound fractions were separated by centrifugation. RNA in supernatant and bound fractions were isolated with TRIzol, and then the $5^{\prime}$ ends of the p21 RNA oligonucleotides were labeled with $\gamma^{32}$ P-ATP by T4 polynucleotide kinase. Labeled p21 oligonucleotides were extracted with phenol-chloroform and precipitated with ethanol and glycerol. Ten microliters of total released RNA and $10 \mu \mathrm{L}$ of bound RNA that was resuspended in $200 \mu \mathrm{L}$ of TE buffer were analyzed on a denaturing $10 \%$ polyacrylamide gel.

\section{Acknowledgments}

We thank the members of the Lou laboratory and Dr. Maria Hatzoglou for helpful discussions, and Dr. Helen Salz and Dr. Jo Ann Wise for critical reading of the manuscript. We thank the following people for providing reagents: Raymond J. Deshaies at California Institute of Technology (UBXD7 and UBXD8 cDNAs); Myriam Gorospe at the National Aging Institute (p21 reporters); Tomohiko Ohta at St. Marianna University School of Medicine, Japan (pET-His6-Ub plasmids); and Changcheng Song at the National Cancer Institute (p97 and A1A2 cDNAs). This work was supported by an NIH grant (NS-049103) and a DOD grant (NF060083) to H.L. G.L. was supported by an NIH grant (CA112094). H.-L.Z. was supported by post-doctoral fellowships from the American Heart Association (0725346B and 09POST2250749). H.-L.Z. and H.L. designed the experiments. H.-L.Z. performed experiments with assistance from C.G. H.-L.Z. and H.L. analyzed the data. G.L. provided inputs into stress treatments. H.-L.Z. and H.L. wrote the paper.

\section{References}

Abdelmohsen K, Pullmann R Jr, Lal A, Kim HH, Galban S, Yang X, Blethrow JD, Walker M, Shubert J, Gillespie DA, et al. 2007. Phosphorylation of HuR by Chk2 regulates SIRT1 expression. Mol Cell 25: 543-557.

Abdelmohsen K, Kuwano Y, Kim HH, Gorospe M. 2008. Posttranscriptional gene regulation by RNA-binding proteins during oxidative stress: Implications for cellular senescence. Biol Chem 389: 243-255.

Abdelmohsen K, Srikantan S, Yang X, Lal A, Kim HH, Kuwano Y, Galban S, Becker KG, Kamara D, de Cabo R, et al. 2009. Ubiquitin-mediated proteolysis of HuR by heat shock. EMBO I 28: 1271-1282.

Acs K, Luijsterburg MS, Ackermann L, Salomons FA, Hoppe T, Dantuma NP. 2011. The AAA-ATPase VCP/p97 promotes 53BP1 recruitment by removing L3MBTL1 from DNA double-strand breaks. Nat Struct Mol Biol 18: 1345-1350.

Alexandru G, Graumann J, Smith GT, Kolawa NJ, Fang R, Deshaies RJ. 2008. UBXD7 binds multiple ubiquitin ligases and implicates p97 in HIF1 $\alpha$ turnover. Cell 134: 804-816.

Amerik AY, Hochstrasser M. 2004. Mechanism and function of deubiquitinating enzymes. Biochim Biophys Acta 1695: 189-207.

Brooks SA. 2010. Functional interactions between mRNA turnover and surveillance and the ubiquitin proteasome system. Wiley Interdiscip Rev RNA 1: 240-252.

Cheadle C, Fan J, Cho-Chung YS, Werner T, Ray J, Do L, Gorospe M, Becker KG. 2005. Control of gene expression during T cell activation: Alternate regulation of mRNA transcription and mRNA stability. BMC Genomics 6: 75.

Chen ZJ, Sun LJ. 2009. Nonproteolytic functions of ubiquitin in cell signaling. Mol Cell 33: 275-286.

Dias SM, Wilson KF, Rojas KS, Ambrosio AL, Cerione RA. 2009. The molecular basis for the regulation of the cap-binding complex by the importins. Nat Struct Mol Biol 16: 930-937.
Doller A, Schlepckow K, Schwalbe H, Pfeilschifter J, Eberhardt W. 2010. Tandem phosphorylation of serines 221 and 318 by protein kinase C $\delta$ coordinates mRNA binding and nucleocytoplasmic shuttling of HuR. Mol Cell Biol 30: 1397-1410.

Fan J, Yang X, Wang W, Wood WH III, Becker KG, Gorospe M. 2002. Global analysis of stress-regulated mRNA turnover by using cDNA arrays. Proc Natl Acad Sci 99: 10611-10616.

Fialcowitz-White EJ, Brewer BY, Ballin JD, Willis CD, Toth EA, Wilson GM. 2007. Specific protein domains mediate cooperative assembly of HuR oligomers on AU-rich mRNAdestabilizing sequences. J Biol Chem 282: 20948-20959.

Franks TM, Singh G, Lykke-Andersen J. 2010. Upf1 ATPasedependent mRNP disassembly is required for completion of nonsense-mediated mRNA decay. Cell 143: 938-950.

Gallouzi IE, Brennan CM, Stenberg MG, Swanson MS, Eversole A, Maizels N, Steitz JA. 2000. HuR binding to cytoplasmic mRNA is perturbed by heat shock. Proc Natl Acad Sci 97: 3073-3078.

Garneau NL, Wilusz J, Wilusz CJ. 2007. The highways and byways of mRNA decay. Nat Rev Mol Cell Biol 8: 113-126.

Gehring NH, Lamprinaki S, Kulozik AE, Hentze MW. 2009. Disassembly of exon junction complexes by PYM. Cell 137: 536-548.

Hieronymus H, Silver PA. 2004. A systems view of mRNP biology. Genes Dev 18: 2845-2860.

Hinman MN, Lou H. 2008. Diverse molecular functions of $\mathrm{Hu}$ proteins. Cell Mol Life Sci 65: 3168-3181.

Hosoda N, Lejeune F, Maquat LE. 2006. Evidence that poly(A) binding protein $\mathrm{C} 1$ binds nuclear pre-mRNA poly(A) tails. Mol Cell Biol 26: 3085-3097.

Ikeda F, Crosetto N, Dikic I. 2010. What determines the specificity and outcomes of ubiquitin signaling? Cell 143: 677-681.

Johnson JO, Mandrioli J, Benatar M, Abramzon Y, Van Deerlin VM, Trojanowski JQ, Gibbs JR, Brunetti M, Gronka S, Wuu J, et al. 2010. Exome sequencing reveals VCP mutations as a cause of familial ALS. Neuron 68: 857-864.

Jung YS, Qian Y, Chen X. 2010. Examination of the expanding pathways for the regulation of p21 expression and activity. Cell Signal 22: 1003-1012.

Keene JD. 2001. Ribonucleoprotein infrastructure regulating the flow of genetic information between the genome and the proteome. Proc Natl Acad Sci 98: 7018-7024.

Keene JD. 2007. RNA regulons: Coordination of post-transcriptional events. Nat Rev Genet 8: 533-543.

Keene JD. 2010. Minireview: Global regulation and dynamics of ribonucleic acid. Endocrinology 151: 1391-1397.

Kim HH, Abdelmohsen K, Lal A, Pullmann R Jr, Yang X, Galban S, Srikantan S, Martindale JL, Blethrow J, Shokat KM, et al. 2008. Nuclear HuR accumulation through phosphorylation by Cdk1. Genes Dev 22: 1804-1815.

Kim W, Bennett EJ, Huttlin EL, Guo A, Li J, Possemato A, Sowa ME, Rad R, Rush J, Comb MJ, et al. 2011. Systematic and quantitative assessment of the ubiquitin-modified proteome. Mol Cell 44: 325-340.

Kuwano Y, Kim HH, Abdelmohsen K, Pullmann R Jr, Martindale JL, Yang X, Gorospe M. 2008. MKP-1 mRNA stabilization and translational control by RNA-binding proteins $\mathrm{HuR}$ and NF90. Mol Cell Biol 28: 4562-4575.

Laroia G, Cuesta R, Brewer G, Schneider RJ. 1999. Control of mRNA decay by heat shock-ubiquitin-proteasome pathway. Science 284: 499-502.

Lebedeva S, Jens M, Theil K, Schwanhausser B, Selbach M, Landthaler M, Rajewsky N. 2011. Transcriptome-wide analysis of regulatory interactions of the RNA-binding protein HuR. Mol Cell 43: 340-352. 
Lee JN, Kim H, Yao H, Chen Y, Weng K, Ye J. 2010. Identification of Ubxd8 protein as a sensor for unsaturated fatty acids and regulator of triglyceride synthesis. Proc Natl Acad Sci 107: 21424-21429.

Linder P, Jankowsky E. 2011. From unwinding to clamping-the DEAD box RNA helicase family. Nat Rev Mol Cell Biol 12: 505-516.

Lukong KE, Chang KW, Khandjian EW, Richard S. 2008. RNAbinding proteins in human genetic disease. Trends Genet 24: 416-425.

Masuda K, Abdelmohsen K, Kim MM, Srikantan S, Lee EK, Tominaga K, Selimyan R, Martindale JL, Yang X, Lehrmann E, et al. 2011. Global dissociation of HuR-mRNA complexes promotes cell survival after ionizing radiation. $E M B O J$ 30: 1040-1053.

Meyer H, Bug M, Bremer S. 2012. Emerging functions of the VCP/p97 AAA-ATPase in the ubiquitin system. Nat Cell Biol 14: 117-123.

Moore MJ. 2005. From birth to death: The complex lives of eukaryotic mRNAs. Science 309: 1514-1518.

Mukherjee N, Lager PJ, Friedersdorf MB, Thompson MA, Keene JD. 2009. Coordinated posttranscriptional mRNA population dynamics during T-cell activation. Mol Syst Biol 5: 288.

Mukherjee N, Corcoran DL, Nusbaum JD, Reid DW, Georgiev S, Hafner M, Ascano M Jr, Tuschl T, Ohler U, Keene JD. 2011. Integrative regulatory mapping indicates that the RNAbinding protein HuR couples pre-mRNA processing and mRNA stability. Mol Cell 43: 327-339.

Peng SS, Chen CY, Xu N, Shyu AB. 1998. RNA stabilization by the AU-rich element binding protein, HuR, an ELAV protein. EMBO J 17: 3461-3470.

Pyle AM. 2011. RNA helicases and remodeling proteins. Curr Opin Chem Biol 15: 636-642.

Ramadan K, Bruderer R, Spiga FM, Popp O, Baur T, Gotta M, Meyer HH. 2007. Cdc48/p97 promotes reformation of the nucleus by extracting the kinase Aurora B from chromatin. Nature 450: 1258-1262.

Ritz D, Vuk M, Kirchner P, Bug M, Schutz S, Hayer A, Bremer S, Lusk C, Baloh RH, Lee H, et al. 2011. Endolysosomal sorting of ubiquitylated caveolin-1 is regulated by VCP and UBXD1 and impaired by VCP disease mutations. Nat Cell Biol 13: 1116-1123.

Schuberth C, Buchberger A. 2008. UBX domain proteins: Major regulators of the AAA ATPase Cdc48/p97. Cell Mol Life Sci 65: 2360-2371.

Srikantan S, Gorospe M. 2012. HuR function in disease. Front Biosci 17: 189-205.

Suzuki M, Otsuka T, Ohsaki Y, Cheng I, Taniguchi T, Hashimoto H, Taniguchi H, Fujimoto T. 2012. Derlin-1 and UBXD8 are engaged in dislocation and degradation of lipidated ApoB-100 at lipid droplets. Mol Biol Cell 23: 800-810.

Tenenbaum SA, Lager PJ, Carson CC, Keene JD. 2002. Ribonomics: Identifying mRNA subsets in mRNP complexes using antibodies to RNA-binding proteins and genomic arrays. Methods 26: 191-198.

Tran EJ, Zhou Y, Corbett AH, Wente SR. 2007. The DEAD-box protein Dbp5 controls mRNA export by triggering specific RNA:protein remodeling events. Mol Cell 28: 850-859.

Verma R, Oania R, Fang R, Smith GT, Deshaies RJ. 2011. Cdc48/ p97 mediates UV-dependent turnover of RNA Pol II. Mol Cell 41: 82-92.

Wang W, Furneaux H, Cheng H, Caldwell MC, Hutter D, Liu Y, Holbrook N, Gorospe M. 2000. HuR regulates p21 mRNA stabilization by UV light. Mol Cell Biol 20: 760-769.

Watts GD, Wymer J, Kovach MJ, Mehta SG, Mumm S, Darvish D, Pestronk A, Whyte MP, Kimonis VE. 2004. Inclusion body myopathy associated with Paget disease of bone and frontotemporal dementia is caused by mutant valosin-containing protein. Nat Genet 36: 377-381.

Wilcox AJ, Laney JD. 2009. A ubiquitin-selective AAA-ATPase mediates transcriptional switching by remodelling a repressor-promoter DNA complex. Nat Cell Biol 11: 1481-1486.

Wilusz CJ, Wilusz J. 2010. Consequences of mRNA wardrobe malfunctions. Cell 143: 863-865.

Xirodimas D, Saville MK, Edling C, Lane DP, Lain S. 2001. Different effects of p14ARF on the levels of ubiquitinated p53 and Mdm2 in vivo. Oncogene 20: 4972-4983.

Xu P, Duong DM, Seyfried NT, Cheng D, Xie Y, Robert J, Rush J, Hochstrasser M, Finley D, Peng J. 2009. Quantitative proteomics reveals the function of unconventional ubiquitin chains in proteasomal degradation. Cell 137: 133-145.

Yamanaka K, Sasagawa Y, Ogura T. 2011. Recent advances in p97/VCP/Cdc48 cellular functions. Biochim Biophys Acta 1823: $130-137$.

Zehmer JK, Bartz R, Bisel B, Liu P, Seemann J, Anderson RG. 2009. Targeting sequences of UBXD8 and AAM-B reveal that the ER has a direct role in the emergence and regression of lipid droplets. J Cell Sci 122: 3694-3702.

Zhou HL, Hinman MN, Barron VA, Geng C, Zhou G, Luo G, Siegel RE, Lou H. 2011. Hu proteins regulate alternative splicing by inducing localized histone hyperacetylation in an RNA-dependent manner. Proc Natl Acad Sci 108: E627E635. 


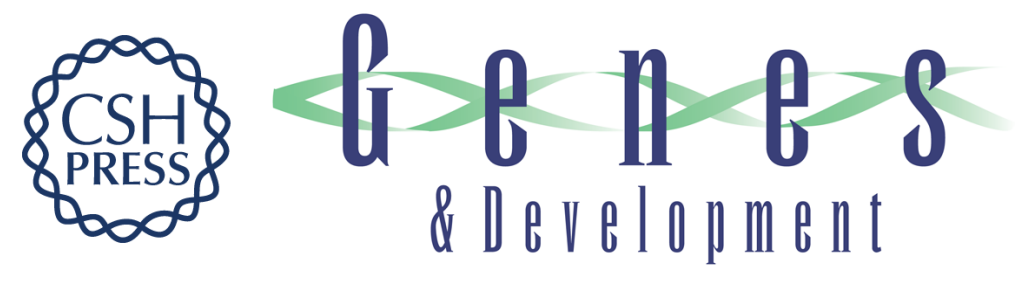

\title{
The p97-UBXD8 complex destabilizes mRNA by promoting release of ubiquitinated HuR from mRNP
}

\author{
Hua-Lin Zhou, Cuiyu Geng, Guangbin Luo, et al.
}

Genes Dev. 2013, 27: originally published online April 25, 2013

Access the most recent version at doi:10.1101/gad.215681.113

\section{Supplemental http://genesdev.cshlp.org/content/suppl/2013/04/11/gad.215681.113.DC1 Material \\ Related Content Protein segregase meddles in remodeling of mRNAprotein complexes Chyi-Ying A. Chen and Ann-Bin Shyu \\ Genes Dev. May , 2013 27: 980-984 \\ References This article cites 58 articles, 18 of which can be accessed free at: http://genesdev.cshlp.org/content/27/9/1046.full.html\#ref-list-1 \\ Articles cited in: \\ http://genesdev.cshlp.org/content/27/9/1046.full.html\#related-urls \\ License \\ Email Alerting Receive free email alerts when new articles cite this article - sign up in the box at the top Service right corner of the article or click here.}

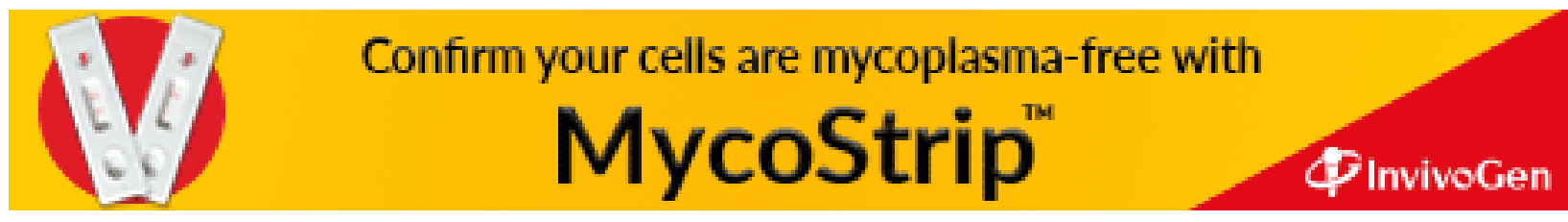

